\title{
SURGICAL TREATMENT OF SUBAORTIC STENOSIS: A SEVENTEEN-YEAR EXPERIENCE
}

Alain Serraf, MD

Joy Zoghby, MD

François Lacour-Gayet, MD

Rémi Houel, MD

Emré Belli, MD

Lorenzo Galletti, MD

Claude Planché, MD
Objective: The aim of the study was to analyze the long-term results of subaortic stenosis relief and the risk factors associated with recurrence and reoperation. Methods: One hundred sixty patients with subaortic stenosis underwent biventricular repair. Before the operation the mean left ventricle-aorta gradient was $80 \pm 35 \mathrm{~mm} \mathrm{Hg}, 57$ patients had aortic regurgitation, and 34 were in New York Heart Association functional class III or IV. Median age at repair was 10 years. For discrete subaortic stenosis $(n=120), 39$ patients underwent isolated membranectomy, 67 underwent membranectomy with associated septal myotomy, and 14 underwent septal myectomy. Tunnel subaortic stenosis $(n=34)$ was treated by myotomy in 10 cases, myectomy in 12, septoplasty in 7, Konno procedure in 3 , and apical conduit in 2 . Aortic valve replacement was performed in 6 cases, mitral valve replacement in 2 cases, and mitral valvuloplasty in 4 cases. Results: There were 5 early $(3.1 \%)$ and 4 late $(4.4 \%)$ deaths. Within $3.6 \pm 3.3$ years a recurrent gradient greater than $30 \mathrm{~mm} \mathrm{Hg}$ was found in 42 patients $(27 \%), 20$ of whom had 26 reoperations. According to multivariable Cox regression analysis survival was influenced by hypoplastic aortic anulus $(P=.01)$ and mitral stenosis $(P=.048)$; recurrence and reoperation were influenced by coarctation and immediate postoperative left ventricular outflow tract gradients. At a median follow-up of $\mathbf{1 3 . 3}$ years, mean left ventricle-aorta gradient was $20 \pm 13 \mathrm{~mm} \mathrm{Hg}$. Relief of the subaortic stenosis improved the degree of aortic regurgitation in $86 \%$ of patients with preoperative aortic regurgitation. Actuarial survival and freedom from reoperation rates at 15 years were $94 \% \pm 1.3 \%$ and $85 \% \pm 6 \%$, respectively. Conclusion: Although surgical treatment provides good results, recurrence and reoperation are significantly influenced by previous coarctation repair and by the quality of initial relief of subaortic stenosis. (J Thorac Cardiovasc Surg 1999;117:669-78) eft ventricular outflow tract (LVOT) obstruction Lcaused by subaortic obstruction covers a wide range of anatomic lesions that can be subdivided into 2 main categories, discrete and diffuse subaortic stenoses. Subaortic stenosis can be isolated or associated with

From the Department of Pediatric Cardiac Surgery, MarieLannelongue Hospital, Le Plessis Robinson, France.

Read at the Seventy-eighth Annual Meeting of The American Association for Thoracic Surgery, Boston, Mass, May 3-6, 1998.

Received for publication May 8, 1998; revisions requested June 30, 1998; revisions received Nov 30, 1998; accepted for publication Dec 2, 1998.

Address for reprints: Alain Serraf, MD. Marie-Lannelongue Hospital, 133 avenue de la Résistance, 92350, Le Plessis Robinson, France. Copyright $\odot 1999$ by Mosby, Inc.

$0022-5223 / 99 \$ 8.00+0 \quad \mathbf{1 2 / 6 / 9 6 4 0 7}$ other heart defects, particularly with multilevel LVOT obstruction. Discrete subaortic stenosis was first reported by Chevers $^{1}$ in 1842 and 2 distinct anatomic types, membranous and fibromuscular, have since been identified. ${ }^{2}$ Although subaortic stenosis is generally considered a progressive lesion, the rate of progression is variable. Apart from the risk of progression of the subaortic stenosis, affected patients face an increased risk of bacterial endocarditis and of aortic insufficiency when fibrous strands extend into the base of aortic leaflets. ${ }^{3}$ Myocardial hypertrophy as a result of the hemodynamic stress may be more or less important and is generally more pronounced at the septal insertion of the membrane. More severe forms of subaortic stenosis are those caused by either short- or long-segment fibromuscular tunnel. ${ }^{4}$ The aortic anulus may be small with a normal aortic valve, but valvular aortic stenosis may coexist. In 
Table I. Anatomy of subaortic stenosis

\begin{tabular}{lr}
\hline & No. \\
\hline Discrete subaortic stenosis & 120 \\
Isolated membrane & 39 \\
Membrane and septal hypertrophy & 81 \\
Tunnel subaortic stenosis & 34 \\
Normal aortic anulus & 28 \\
Hypoplastic aortic anulus & 6 \\
Accessory mitral valve tissue & 6 \\
\hline
\end{tabular}

those cases concentric left ventricular hypertrophy is usual. Subaortic stenosis may also be the consequence of abnormal mitral valve insertion ${ }^{5}$ or accessory tissue, ${ }^{6}$ abnormal insertion of mitral papillary muscle, ${ }^{7}$ abnormal muscular bands within the LVOT, ${ }^{8}$ or posterior displacement of the infundibular septum without ventricular septal defect ${ }^{9}$ associated or not with a subaortic membrane. Finally, subaortic stenosis can be part of a more complex syndrome of multilevel left ventricular obstruction (Shone complex) ${ }^{10}$ for which the optimal strategy remains to be defined.

There is little controversy with respect to the necessity for surgical intervention. Controversies remain, however, regarding surgical timing and technique. Although early surgical removal of subaortic membranes with or without septal myotomy or myectomy seems to prevent the development of aortic insufficiency, recurrence still remains a long-term complication. In tunnel subaortic stenosis the situation is rather different. Early surgical intervention is generally conservative and residual stenosis is frequent, leading to reoperations. We report here our 17-year institutional experience with the surgical treatment of subaortic stenosis in patients with intact interventricular septum.

\section{Patients and methods}

From January 1980 to June 1997, among children with any form of subaortic stenosis who were referred to our institution for surgical relief, 160 had an intact ventricular septum, had concordant ventriculoarterial connections, and were candidates for biventricular repair (Table I). To analyze a homogeneous group of patients, those with ventricular septal defect were excluded from the study. Patients in whom a subaortic stenosis developed after closure of a ventricular septal defect and those in whom the subaortic stenosis was caused by a tumor were also excluded. Within the group of patients with Shone syndrome, those who had a non-apex-forming left ventricle were also excluded. Finally, patients undergoing operation for hypertrophic obstructive cardiomyopathy were also excluded. There were 107 male and 53 female patients. The median age at intervention was 10 years (range 0.1-30 years). Most patients $(\mathrm{n}=126)$ were symptom-free and in
Table II. Associated lesions

\begin{tabular}{lc}
\hline & No. \\
\hline Atrial septal defect & 7 \\
Ostium secundum & 5 \\
Ostium primum & 2 \\
Aortic valve & 81 \\
Valvular stenosis & 10 \\
Annular stenosis & 14 \\
Regurgitation & 57 \\
Mitral valve & 22 \\
Stenosis & 13 \\
Regurgitation & 9 \\
Isthmic coarctation & 26 \\
Supravalvular aortic stenosis & 2 \\
Double-chambered right ventricle & 1 \\
\hline
\end{tabular}

New York Heart Association (NYHA) functional class I or II and 34 were in NYHA functional class III or IV.

Preoperative assessment was performed by angiography and echocardiography in 101 cases and by echocardiography alone in 59 cases. Gradient across the LVOT was calculated at catheterization by nonsimultaneous peak-to-peak systolic gradients. For patients undergoing only Doppler echocardiographic assessment the formula of Beekman and associates ${ }^{11}$ was applied to approximate catheter-derived peak-to-peak LVOT gradients. Mean gradient across the LVOT was $80 \pm 34$ $\mathrm{mm} \mathrm{Hg}$. Aortic valve regurgitation was present in 57 patients, and was qualitatively assessed on the basis of aortic root angiography when available or on the basis of the size of the color Doppler regurgitant flow at the valve level, as described by Perry and colleagues. ${ }^{12}$ It was mild in 41 cases, moderate in 15 cases, and severe in 1 case. Aortic valve stenosis was present in 24 patients and 14 had a hypoplastic aortic anulus. Mitral valve stenosis was found in 13 patients and 9 had mitral valve regurgitation. The subaortic lesion responsible for the gradient was found to be an isolated localized discrete fibrous stenosis (membrane) in 39 patients; this was associated with localized muscular hypertrophy in 81 other patients. Long-segment diffuse tunnel subaortic stenosis was present in 34 patients, 15 of whom also had a subaortic membrane. In 6 patients the subaortic stenosis was particularly related to an abnormal insertion of mitral papillary muscle or to accessory anterior mitral leaflet tissue. Associated anomalies are listed in Table II.

Surgery was indicated in presence of symptoms or an aortic regurgitation, regardless of the gradient across the LVOT. In symptom-free patients the decision for surgical repair was taken when the peak systolic LVOT gradient was $50 \mathrm{~mm} \mathrm{Hg}$ or more. Previous operations had been performed in 32 cases. Coarctation repair had been undertaken in 26 cases, aortic valve commissurotomy had been undertaken in 5 cases, and 2 patients had undergone repair of a partial atrioventricular canal.

Operative procedures. Operations (Figs 1 and 2) were always conducted with hypothermic continuous cardiopulmonary bypass. Myocardial protection was ensured by crystalloid or blood cardioplegic administration antegradely, ret- 


\section{Discrete subaortic stenosis (120)}

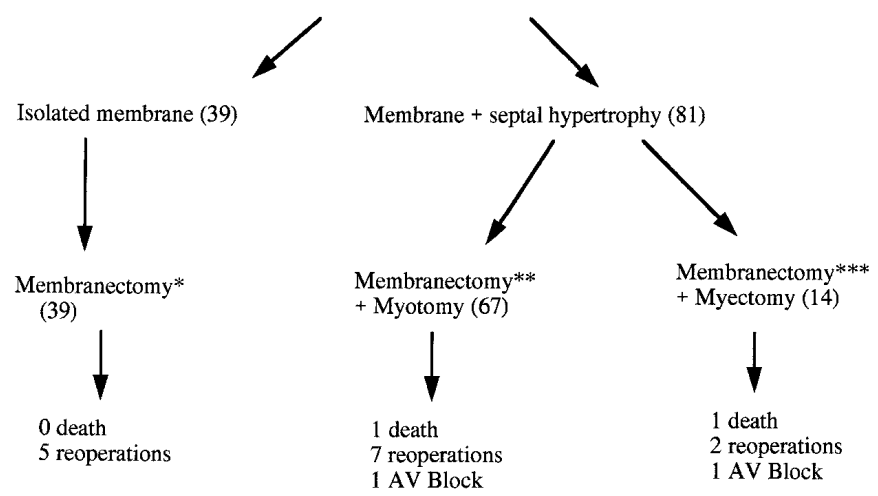

Fig 1. Surgical procedures for discrete subaortic stenosis and results. Asterisk indicates 3 cases of concomitant aortic valve commissurotomy; double asterisk indicates 4 cases of concomitant aortic valve commissurotomy; triple asterisk indicates 1 case of concomitant aortic valve commissurotomy. $A V$, Atrioventricular.

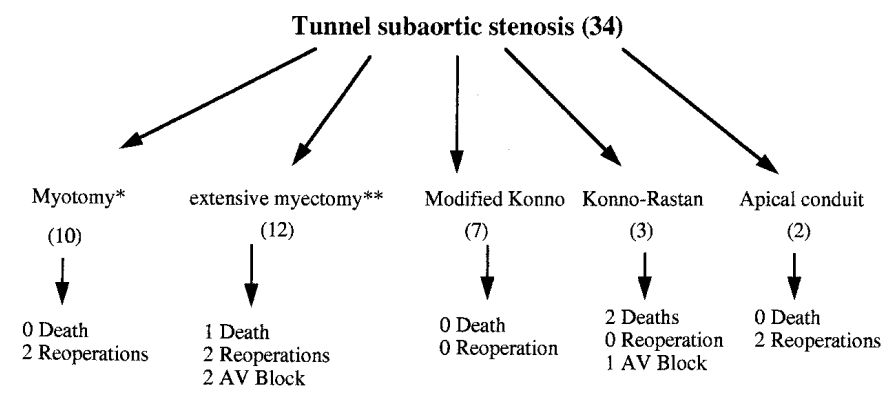

Fig 2. Surgical procedures for tunnel subaortic stenosis and results. Asterisk indicates 3 cases of concomitant aortic valve commissurotomy; double asterisk indicates 4 cases of concomitant aortic valve commissurotomy. $A V$, Atrioventricular.

rogradely, or both. The mean cardiopulmonary bypass time was $70 \pm 43$ minutes and the mean crossclamp time was $32 \pm$ 20 minutes. The obstructive lesion was approached through an oblique aortotomy in all cases. In 7 cases a combined approach through aortotomy and right ventriculotomy was necessary. Early in the experience subaortic membranes were removed with sharp dissection without any adjunct of septal myotomy or myectomy. Attention was always taken to avoid injury to both the conduction tissue and the mitral valve. The myotomy consisted of a deep incision made at the nadir of the right coronary aortic cusp into the septal muscle that protruded into the LVOT. When septal myectomy was performed a second incision was made caudal to the commissure between right and left coronary aortic cusps and both incisions were joined at their upper and lower edges. A deep wedge septal resection was then performed. When either myotomy or myectomy was performed the goal was to obtain a free patent subaortic area that would admit without friction a Hegar dilator matched with body area. Isolated membranectomy was performed in 39 patients; membranectomy was associated with septal myotomy in 77 cases and with myectomy in 26 cases. At initial operation it was the rule to remain as conser- vative as possible, even leaving untouched an hypoplastic aortic anulus. Seven patients with long-segment diffuse tunnel subaortic stenosis and normal aortic valves underwent, through a combined approach, a modified Konno procedure with patch septoplasty ${ }^{13}$ as the initial operation. In these patients the LVOT was inspected through the aortotomy. The right ventricular infundibulum was then opened and the septum was incised after introduction of a Hegar dilator through the aortic valve. Subaortic obstruction was resected and a polytetrafluoroethylene patch was used to reconstruct the septum. The upper edge of the patch was anchored to the aortic anulus by placement of interrupted sutures tied within the aortic lumen. This procedure was considered to avoid late aortic valve insufficiency. Three patients with tunnel subaortic stenosis and hypoplastic aortic anulus underwent a Konno-Rastan ${ }^{14,15}$ procedure and 2 others with the Shone syndrome underwent apical conduit insertion. In 6 cases the treatment of subaortic stenosis consisted of resection of accessory mitral valve tissue. Aortic valve commissurotomy was associated with this resection in 15 patients, and 6 others underwent aortic valve replacement. None of the patients with preoperative aortic valve regurgitation underwent valvu- 


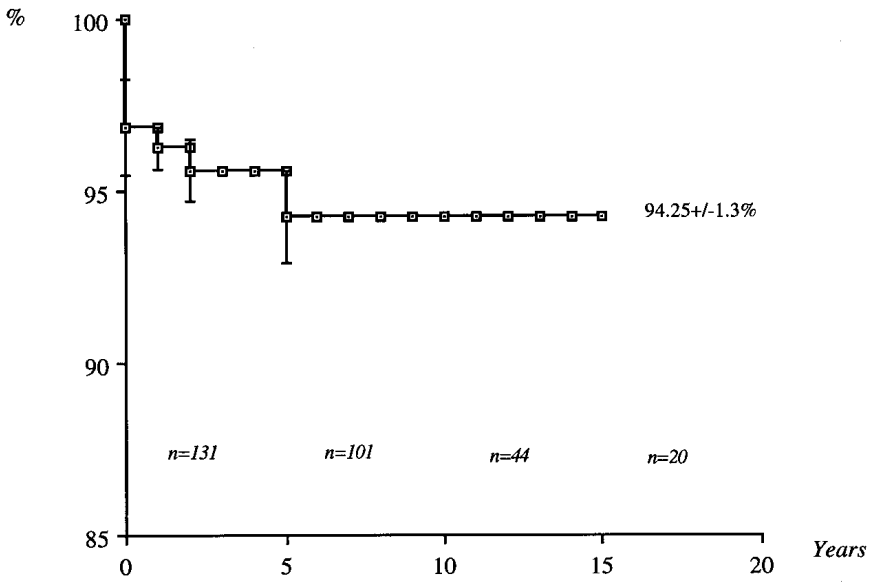

Fig 3. Actuarial survival at 15 years.

Table III. Postoperative evolution of aortic valve regurgitation according to the preoperative grade

\begin{tabular}{lccc}
\hline $\begin{array}{l}\text { Aortic valve } \\
\text { regurgitation }\end{array}$ & Preoperative & Postoperative & $\begin{array}{c}\text { Late } \\
\text { follow-up }\end{array}$ \\
\hline None & 103 & 131 & 123 \\
Mild & 41 & 13 & 11 \\
Moderate & 15 & 11 & 11 \\
Severe & 1 & 0 & 0 \\
\hline
\end{tabular}

loplasty. Mitral valve repair was performed in 4 patients and 2 others underwent mitral valve replacement.

Follow-up. All but 10 foreign patients were regularly reviewed by their referring cardiologist, achieving a median follow-up of 13.3 years (range 1.2-17.9 years). Particular attention was given to the recurrence of subaortic stenosis and to the function of the aortic and mitral valves.

Statistical analysis. Data are expressed as mean values with $70 \%$ confidence intervals. Time-related events were examined by Kaplan-Meier actuarial methods. Bivariate correlation coefficients for interval and ordinal data were obtained by the Pearson rank correlations. Risk factors associated with early and overall mortality rates were assessed by univariate analysis, as well as for recurrent subaortic stenosis and reoperation. The $t$ test was used for continuous variables and the $\chi^{2}$ test was used for dichotomous variables. Multivariable logistic regression was used to assess independent factors affecting early mortality rate. Cox regression models were used to assess independent factors affecting long-term survival and recurrence of subaortic stenosis and reoperation.

\section{Results}

Early mortality and morbidity. There were 5 early deaths $(3.1 \%, 70 \%$ confidence interval $1.5 \%-5.2 \%)$.
Among them 3 patients were first seen with tunnel subaortic stenosis, 1 was first seen with already compromised left ventricular function (NYHA functional class III-IV), and the other 2 were first seen with severe preoperative aortic valve regurgitation. One of the last 2 underwent an unsuccessful Konno-Rastan aortoventriculoplasty with mechanical aortic valve replacement. Two other postoperative deaths occurred among patients with discrete subaortic stenosis; 1 patient died of iatrogenic severe aortic regurgitation and the other died of secondary tamponade. At univariate statistical analysis only preoperative NYHA functional classes III and IV and the older age at operation significantly increased the risk of early death $(P=.0002$ and $P=$ .006 , respectively). At multivariable analysis preoperative NYHA functional class was found to be an independent risk factor for early death $(P=.008)$. Five patients required pacemaker implantation for complete atrioventricular block as a result of the operation.

Overall mortality and long-term follow-up. There were 4 late deaths $(4.37 \%, 70 \%$ confidence interval $2.57 \%-6.75 \%) ; 2$ occurred after a second reoperation, 1 was of a patient who underwent apical conduit insertion at reoperation and died 6 months later of severe myocardial dysfunction, and 1 was of a patient who died of organic chronic renal failure. Actuarial survival at 15 postoperative years was $94.25 \% \pm 1.34 \%$ (Fig 3).

Overall mortality rate was essentially influenced by anatomic factors, namely hypoplastic aortic anulus $(P$ $=.0001)$, mitral stenosis $(P=.0026)$, tunnel form of subaortic stenosis $(P=.01)$ and existence of coarctation $(P=.018)$. Multivariable analysis showed that hypoplastic aortic anulus $(P=.01$, coefficient \pm SD $1.129 \pm 0.32)$ and mitral stenosis $(P=.048$, coefficient 


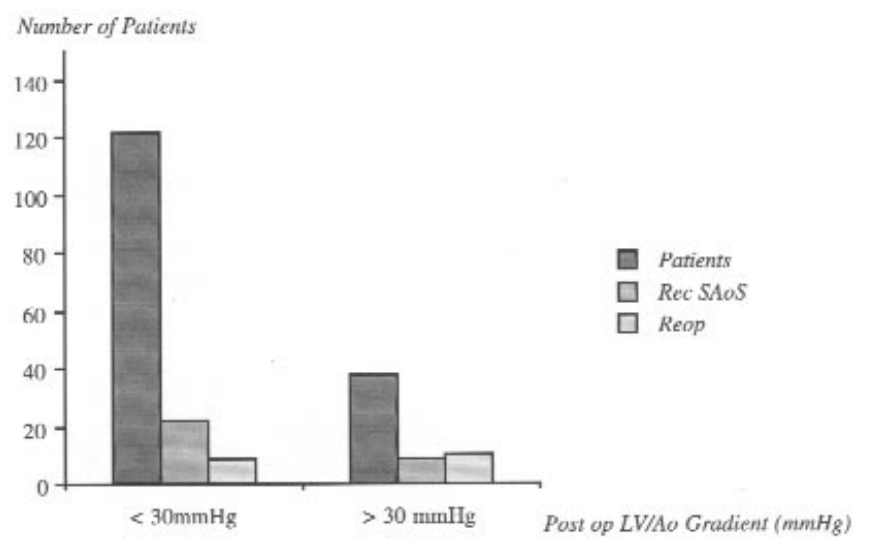

Fig 4. Bar graph shows recurrent subaortic stenosis (Rec $S A o S)$ and reoperation (Reop) with respect to immediate postoperative left ventricle-aorta $(L V / A o)$ gradient.

Table IV. Reoperations

\begin{tabular}{lcc}
\hline & $\begin{array}{c}\text { First } \\
\text { reoperation }\end{array}$ & $\begin{array}{c}\text { Second } \\
\text { reoperation }\end{array}$ \\
\hline Recurrent subaortic stenosis & 17 & 4 \\
Second membranectomy & 14 & 0 \\
plus myectomy & & \\
Konno-Rastan procedure & 0 & 0 \\
Ross-Konno procedure & 2 & $1^{*}$ \\
Apical conduit & 1 & 1 \\
Aortic endocarditis coarctation & 1 & 0 \\
Aortic valve replacement & 1 & 1 \\
Aortic homograft & 0 & 1 \\
Apical conduit dysfunction & 2 & $1^{*}$ \\
Conduit replacement & 2 & \\
\hline
\end{tabular}

*Death at reoperation.

\pm SD $0.949 \pm 0.51$ ) were independent predictors for overall mortality rate.

At a median follow-up of 13.3 years all but 2 survivors were in NYHA class I or II and those 2 were in NYHA class III or IV. Two other patients have successfully undergone liver transplantation, both for liver cirrhosis that was related to biliary atresia in 1 case and to sclerosing cholangitis in the other. The mean gradient across the LVOT was $20 \pm 13 \mathrm{~mm} \mathrm{Hg}$. Twenty-two patients had an aortic valve insufficiency; this was mild in 11 cases and moderate in 11 cases.

Aortic valve function (Table III). Seventy-six patients were known before the operation to have aortic valve dysfunction. Nineteen had isolated aortic valve stenosis, 51 had isolated aortic valve regurgitation, and 6 had aortic valve disease with both regurgitation and stenosis. The degree of aortic regurgitation at initial examination correlated with age $(r=0.16, P=$

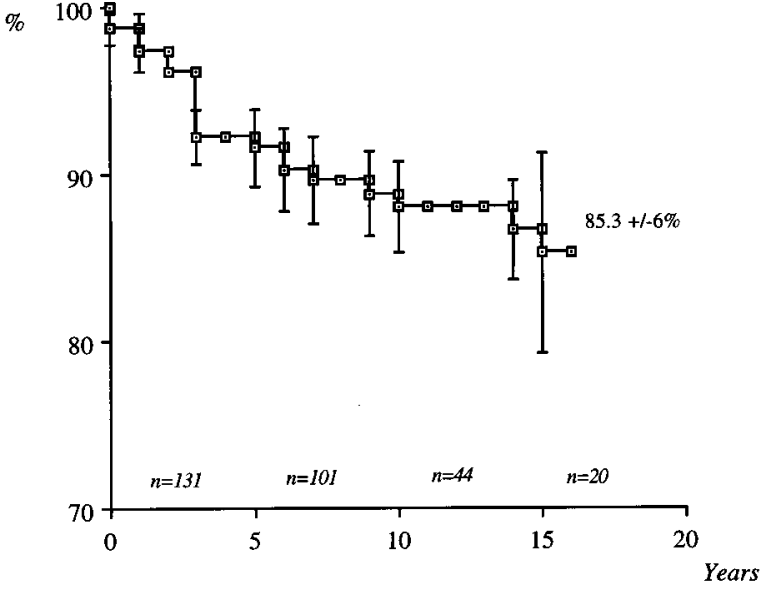

Fig 5. Actuarial freedom from reoperation at 15 years.

.02) but not with LVOT gradient ( $r=-0.02, P=.38$ ). Relief of the subaortic stenosis improved the degree of aortic regurgitation in 49 cases and stabilized it in 4 cases, but aortic regurgitation was worsened in 2 patients with preoperative aortic regurgitation and appeared in 21 without preoperative aortic regurgitation. In the latter patients aortic regurgitation was mild, however, and only 1 underwent reoperation for aortic endocarditis. All the others did not demonstrate aggravation of the aortic regurgitation during the length of follow-up. No preoperative factors tested (age, preoperative gradient, surgical technique, anatomy, and preoperative valve function) were found to influence the outcome of aortic valve function.

Postoperative mitral valve function. Preoperative mitral valve stenosis was diagnosed in 13 patients. It 


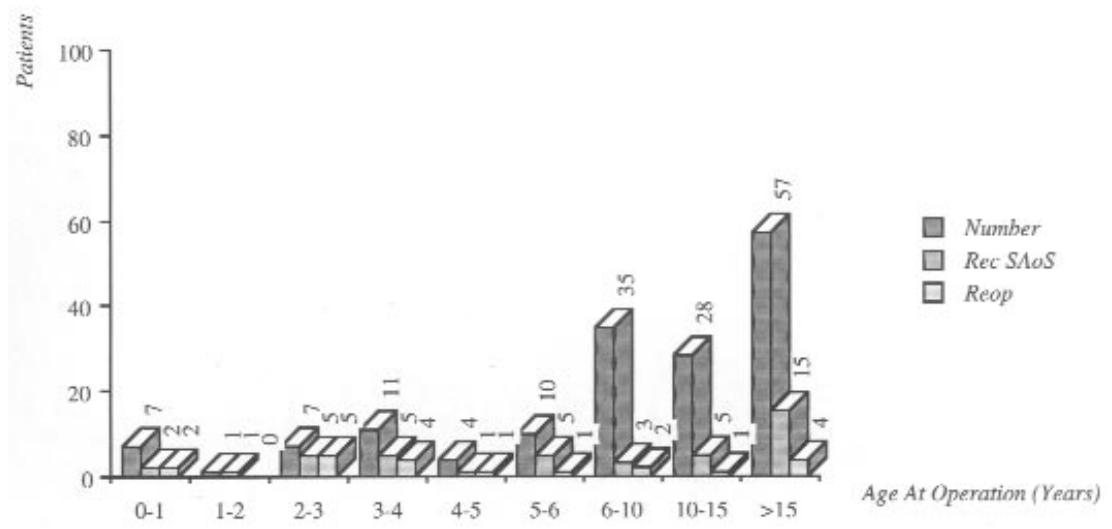

Fig 6. Stratification of population age at initial operation relative to recurrent subaortic stenosis (Rec SAoS) and reoperation (Reop).

was due mainly to papillary muscle fusion; however, in 3 cases it was necessary to add a procedure for relief of mitral stenosis. Mitral regurgitation was present in 9 patients before the operation; 2 underwent mechanical mitral valve replacement and 3 had mitral valvuloplasty. Eleven patients had a mild to moderate mitral regurgitation develop after the operation.

Recurrence of subaortic stenosis and reoperations. The gradient across the LVOT before initial operation did not correlate with preoperative age $(r=0.11$, $P=.08)$. It was reduced in all survivors from $80 \pm 34$ $\mathrm{mm} \mathrm{Hg}$ to $16 \pm 3.5 \mathrm{~mm} \mathrm{Hg}$. No significant differences $(P>.05$ for all variables) in reduction of the LVOT gradient were observed in association with preoperative anatomy, LVOT gradient, associated aortic valve disease, surgical technique, and age. Particularly, there was no difference when myotomy was performed rather than myectomy.

All traced patients had an available Doppler echocardiographic study within 1 year of the completion of this study. Forty-two patients $(27 \%, 70 \%$ confidence interval 23\%-31\%) had a gradient greater than $30 \mathrm{~mm} \mathrm{Hg}$ develop across the LVOT. The mean delay for reappearance of a gradient across the LVOT was $3.65 \pm 3.35$ years. Statistical analysis revealed that several factors could be predictors for recurrence of the subaortic stenosis. In univariate analyses anatomic, surgical, and hemodynamic factors were strong predictors for recurrence. The anatomic factors were relative hypoplasia of aortic anulus $(P=.02)$, tunnel form $(P=.018)$, and existence of aortic coarctation $(P=.0008)$. Myectomy and isolated membranectomy were associated with higher rates of recurrence $(P=.03$ and $P=.02$, respectively), as were higher preoperative gradients across the LVOT $(P=.05)$. There was a strong positive correlation
( $r=0.3, P=.0001)$ between immediate postoperative left ventricle-aorta gradient and the rate of recurrence. Patients with an immediate postoperative left ventricle-aorta gradient had a higher rate of recurrence (Fig 4). In the multivariable Cox regression analysis existence of aortic coarctation $(P=.005$, coefficient $\pm \mathrm{SD}$ $1.943 \pm 0.6)$ and the immediate postoperative gradient across the LVOT $(P=.005$, coefficient \pm SD $1.732 \pm$ 0.70 ) were independent risk factors for recurrence.

Twenty patients $(12.9 \%, 70 \%$ confidence interval 9.96\%-16.3\%) were reoperated on within a mean delay of $5.3 \pm 4.6$ years (Table IV). Freedom from reoperation was $85.3 \% \pm 6 \%$ (Fig 5). Recurrent subaortic stenosis was the cause for reoperation in 17 cases $(10.9 \%, 70 \%$ confidence interval $8.2 \%-14.1 \%$ ), with a mean gradient across the LVOT of $95 \pm 29 \mathrm{~mm} \mathrm{Hg}$. Aortic valve endocarditis in 1 patient and apical conduit dysfunction in 2 patients were the other reasons for reoperation. Fourteen patients underwent new membrane excision associated with myectomy, 1 underwent a mechanical aortic valve replacement, 2 underwent Ross-Konno procedures, 1 underwent an apical conduit insertion, and 2 underwent apical conduit replacement. There were no early deaths after reoperation. Six patients underwent a second reoperation for aortic prosthetic valve endocarditis in 1 case, recurrent subaortic stenosis in 4 cases, and apical conduit obstruction in 1 case. They underwent aortic valve replacement with an aortic homograft in 1 case, Konno-Rastan aortoventriculoplasty in 3 cases, apical conduit insertion in 1 case, and apical conduit replacement in 1 case. The last 2 patients both died after reoperation, and postmortem examination revealed a severe endocardial fibroelastosis in both. Statistical analysis revealed that reoperation rate was influenced in univariate analyses by the presence of a hypoplastic aor- 
tic anulus $(P=.014)$, presence of an aortic coarctation $(P=.005)$, younger age at initial operation $(P=.014$; Fig 6), and the immediate postoperative gradient across the LVOT $(P=.0001)$. By multivariable Cox regression analysis, existence of aortic coarctation $(P=.045$, coefficient \pm SD $0.942 \pm 0.38)$ and the immediate postoperative gradient across the LVOT $(P=.009$, coefficient \pm SD $1.522 \pm 48$ ) were again independent predictors of reoperation.

\section{Discussion}

Subaortic stenosis occurs at between $8 \%$ to $30 \%$ in all forms of left ventricular outflow tract obstruction. ${ }^{16}$ The anatomic spectrum, natural history, and progressive nature of this lesion have been well documented. ${ }^{17}$ There remains, however, considerable uncertainty about the rapidity of progression and the timing of surgical repair. ${ }^{18-20}$ Although significant left ventricular hypertrophy and aortic insufficiency are clear indications for surgery, controversy persists wether to remove the membrane in symptom-free patients with an isolated membrane. ${ }^{21}$ In addition to the timing of surgical repair, the surgical technique remains an area of discussion.

Several theories have been advanced to explain the acquired nature of this lesion. It is rarely present in neonates and young children and has not been reported antenatally. ${ }^{16}$ Recently, several rheologic Doppler echocardiography-based studies tried to elucidate the pathologic process for development of discrete subaortic stenosis. ${ }^{22}$ Cape and coworkers ${ }^{23}$ proposed a 4-stage etiology for the development and progression of discrete subaortic stenosis. Subtle morphologic abnormalities in the LVOT, such as a steeper aortoseptal angle, result in an altered septal shear stress, which triggers a genetic predisposition leading to cell proliferation and structures in the LVOT. Therefore any surgical treatment should, in addition to relieving the subaortic stenosis, attempt to treat the anatomic abnormality causing increased septal shear stress. In light of this etiologic theory, it is not surprising that recurrence after resection of subaortic membrane only is common in most published series. ${ }^{24}$ In this series the recurrence rate was $27.1 \%$ and the reoperation rate was $12.1 \%$. Among the various analyzed predicting factors, only the presence of an isthmic coarctation and the quality of primary surgical relief were independent risk factors. To the best of our knowledge the former factor has not previously been stressed as a variable predictive of recurrence. On the basis of this result one may consider the possibility of a more pronounced abnormal left ventricular-aorta junction, which could cause flow disturbances leading to an aortic coarctation soon after birth and related to subaortic membrane. Therefore in the presence of an aortic coarctation the subaortic area should be regularly assessed, particularly after previous subaortic membrane resection. In addition, patients with residual left ventricle-aorta gradient higher than $30 \mathrm{~mm} \mathrm{Hg}$ at the end of bypass should undergo reoperation with a more aggressive subaortic resection during the same operating session.

Myectomy has been favored by several authors ${ }^{25}$ who demonstrated better initial and long-term results. Moreover, it has been suggested that postoperative residual gradients are related to postoperative sympathetic tone. ${ }^{26}$ Our experience does not concur with this finding. First, in accordance with the findings of Brauner and colleagues, ${ }^{27}$ the higher the early postoperative gradients, the higher the rate of recurrence, indicating that the participation of sympathetic tone should not be overestimated. Second, we were not able to find any difference between myotomy and myectomy in either the early or the late postoperative status. Among 145 traced survivors in this series, 42 had a left ventricle- aorta gradient greater than $30 \mathrm{~mm} \mathrm{Hg}$ develop irrespective of the initial surgical technique employed, clearly indicating that the anatomic substrate for development of the membrane had not been treated. Because myectomy was particularly performed in cases of tunnel forms of subaortic stenosis, however, our results are probably biased by the low number of myectomies performed in cases of discrete subaortic stenosis.

Early relief of the subaortic membrane has been advocated by several authors, ${ }^{27-29}$ who argue that it reduces the rate of recurrence as well as the risk of later development of aortic insufficiency. In this series an age younger than 5 years was a significant risk factor for recurrence in univariate but not multivariate analyses. This result also concurs with the findings of Brauner and colleagues ${ }^{27}$; however, the results of this study indicate that age at initial operation has no impact on the future evolution of an aortic insufficiency and that insufficiency is generally improved by resection of the membrane regardless of the age at operation.

Tunnel subaortic stenosis represents a more severe and more challenging cause of left ventricular outflow tract obstruction, particularly when symptoms start early in life. In this series, although multivariate analysis did not point out this anatomic form as an independent risk factor for overall mortality and recurrence rates, in univariate analyses it was associated with a higher overall mortality rate and a higher reoperation rate, along with other factors of the Shone complexnamely, hypoplastic aortic anulus, mitral stenosis, and existence of coarctation. 
Several surgical options are available for treatment of this lesion, depending on the size and function of the aortic valve. It has been our policy not to treat aggressively any of these anatomic forms at initial operation, and most patients in this series therefore underwent as the first procedure an extensive septal myectomy, associated with aortic commissurotomy in 4 cases. When myectomy did not seem to be an adequate surgical procedure, another surgical option was employed. Early in the experience, 2 patients younger than 1 year with a very severe form received an apical conduit at the initial operation and 2 others underwent Konno-Rastan procedures. There were 3 early deaths in this group, 1 of a patient who underwent extensive myectomy only and 2 of patients who underwent Konno-Rastan procedures. Although the rate of reoperation was high in this cohort of patients, it provided an adequate relief of subaortic stenosis as long as 16 years after the procedure. The recent application of the Ross-Konno procedure as the initial operation in infants with tunnel subaortic stenosis and diminutive aortic anulus ${ }^{30}$ has opened a new alternative for definitive treatment of this anomaly. Use of pulmonary autograft with long-term durability and growth potential, avoidance of prosthetic valves, and early repair should make this surgical procedure the technique of choice for selected patients. When the aortic anulus was of adequate size, the modified Konno procedure with a patch septoplasty and conal enlargement ${ }^{31}$ was performed in 7 patients as the primary operation without operative death or atrioventricular block, whereas the others underwent septal myectomy. Both techniques were satisfactory for LVOT gradient relief; however, none of the patients who underwent patch septoplasty had recurrence, whereas 8 who underwent septal myectomy required reoperation for recurrence.

The diagnosis of subaortic stenosis covers a large range of anatomic anomalies and requires a careful preoperative analysis by Doppler echocardiograpy. Discrete subaortic stenosis can be cured in most patients by membranectomy associated with either myotomy or myectomy. Because the anatomic substrate is not addressed by these surgical techniques, however, recurrences are likely during long-term follow-up, particularly in patients who have undergone previous operations for an aortic coarctation and those who have a less than optimal relief of the LVOT gradient. In this subset of patients the optimal surgical technique remains to be described. Intraoperative recording of left ventricleaorta gradient, however, either by transesophageal echocardiography or by pressure measurement, remains an important tool for more aggressive subaortic resection in case of residual gradient greater than $30 \mathrm{~mm} \mathrm{Hg}$. Tunnel subaortic stenosis represents a more severe and more challenging cause of left ventricular outflow tract obstruction. According to the size and function of the aortic valve, the Ross-Konno procedure or the modified Konno procedure by patch septoplasty seems to be the appropriate surgical technique. In all cases it appears that relief of the subaortic stenosis ultimately improves aortic valve function.

We are grateful to Philippe Hervé for his statistical assistance.

\section{REFERENCES}

1. Chevers N. Observations on the diseases of the orifice and valves of the aorta. Guys Hosp Rep 1842;7:387-442.

2. Kelly DT, Wulfsberg BA, Rowe RD. Discrete subaortic stenosis. Circulation 1972;46:309-22.

3. Feigl A, Feigl D, Lucas RV Jr, Edwards JE. Involvement of the aortic valve cusps in discrete subaortic stenosis. Pediatr Cardiol 1984;5:185-90.

4. Maron BJ, Redwood DR, Roberts WC, Henry WL, Morrow AG, Epstein SE. Tunnel subaortic stenosis: left ventricular outflow tract obstruction produced by fibromuscular tubular narrowing. Circulation 1976;54:404-16.

5. Rosenquist GC, Clark EB, McAllistr HA, Bharati S, Edwards JE. Increased mitral aortic separation in discrete subaortic stenosis. Circulation 1979;60:70-4.

6. Haartyanszky I, Kadar K, Bojeldein S, Bodor G. Mitral valve anomalies obstructing left ventricular outflow. Eur J Cardiothorac Surg 1997;12:504-6.

7. Imoto Y, Kado H, Yasuda H, Tominaga R, Yasui H. Subaortic stenosis caused by anomalous papillary muscle of the mitral valve. Ann Thorac Surg 1996;62:1858-60.

8. Moulaert AJ, Oppenheimer-Dekker A. Anterolateral muscle bundle of the left ventricle, bulboventricular flange and subaortic stenosis. Am J Cardiol 1976;37:78-81.

9. Ozkutlu S, Tokel NK, Saraçlar M, Alehan D, Yurdakul Y, Ruacan S. Posterior deviation of left ventricular outflow tract septal components without ventricular septal defect. Heart 1997;77:242-6.

10. Brauner RA, Laks H, Drinkwater DC, Scholl F, McCaffery S. Multiple left heart obstruction (Shone's anomaly) with mitral valve involvement: long term outcome. Ann Thorac Surg 1997; 64:721-9.

11. Beekman RH, Rocchini AP, Gillon JH, Mancini GB. Hemodynamic determinants of the peak systolic left ventricular-aortic pressure gradient in children with valvar aortic stenosis. Am J Cardiol 1992;69:813-5.

12. Perry GJ, Helmcke F, Nanda NC, Byard C, Soto B. Evaluation of aortic insufficiency by Doppler color flow mapping. J Am Coll Cardiol 1987;9:952-9.

13. Cooley DA, Garrett JR. Septoplasty for left ventricular outflow tract obstruction without aortic valve replacement: a new technique. Ann Thorac Surg 1986;42:445-8.

14. Konno S, Imai Y, Iida Y, Nakajima M, Tatsuno K. A new method for prosthetic valve replacement in congenital aortic stenosis associated with hypoplasia of the native aortic valve ring. $\mathrm{J}$ Thorac Cardiovasc Surg 1975;70:909-17. 
15. Rastan H, Koncz J. Aortoventriculoplasty: a new technique for the treatment of left ventricular outflow tract obstruction. J Thorac Cardiovasc Surg 1976;71:920-7.

16. Shem-Tov A, Schneeweiss A, Motro M, Neufeld HN. Clinical presentation and natural history of mild discrete subaortic stenosis: follow-up of 1-17 years. Circulation 1986;66:509-12.

17. Wright GB, Keane JF, Nadas AS, Bernhard WF, Castaneda AR. Fixed subaortic stenosis in the young: medical and surgical course in 83 patients. Am J Cardiol 1983;52:830-5.

18. Freedom RM, Fowler RS, Duncan WJ. Rapid evolution form "normal" left ventricular outflow tract to fatal subaortic stenosis in infancy. Br Heart J 1981;45:605-9.

19. Somerville J, Stone S, Ross D. Fate of patients with fixed subaortic stenosis after surgical removal. Br Heart J 1980;43:629-47.

20. Freedom RM, Pelech A, Brand A, Vogel M, Olley PM, Smallhorn $\mathrm{J}$, et al. The progressive nature of subaortic stenosis in congenital heart disease. Int J Cardiol 1985;8:137-43.

21. Bezold LI, Smith EO, Kelly K, Colan SD, Gauvreau K, Geva T. Development and validation of an echocardiographic model for predicting progression of discrete subaortic stenosis in children. Am J Cardiol 1998;81:314-20.

22. Gewillig M, Daenen W, Dumoulin M, Van Der Hauwaert L. Rheologic genesis of discrete subvalvular aortic stenosis: a Doppler echocardiographic study. J Am Coll Cardiol 1992;19: 818-24.

23. Cape EG, Vanauker MD, Sigfusson G, Tacy TA, Del Nido PJ. Potential role of mechanical stress in the etiology of pediatric heart disease: septal shear stress in subaortic stenosis. J Am Coll Cardiol 1997;30:247-54.

24. Van Son JA, Schaff HV, Danielson GK, Hagler DJ, Puga FJ. Surgical treatment of discrete and tunnel subaortic stenosis: late survival and risk of reoperation. Circulation 1993;88(Pt 2):159-69.

25. Lavee J, Porat L, Smolinsky A, Hegesh J, Neufeld HN, Goor DA. Myectomy versus myotomy as an adjunct to membranectomy in the surgical repair of discrete and tunnel subaortic stenosis. J Thorac Cardiovasc Surg 1986;92:944-9.

26. Ziskind Z, Goor DA, Peleg E, Mohr R, Lusky A, Smolinsky A. The perioperative fate of residual gradients after repair of discrete subaortic stenosis and time-related blood levels of catecholamines. J Thorac Cardiovasc Surg 1988;96:423-6.

27. Brauner R, Laks H, Drinkwater DC Jr, Shvarts O, Eghbali K, Galindo A. Benefits of early surgical repair in fixed subaortic stenosis. J Am Coll Cardiol 1997;30:1835-42.

28. Coleman DM, Smallhorn JF, McCrindle BW, Williams WG, Freedom RM. Postoperative follow-up of fibromuscular subaortic stenosis. J Am Coll Cardiol 1994;24:1558-64.

29. Rizzoli G, Tiso E, Mazzucco A, Daliento L, Rubino M, Tursi V, et al. Discrete subaortic stenosis. Operative age and gradient as predictors of late aortic valve incompetence. J Thorac Cardiovasc Surg 1993;106:95-104.

30. Starnes VA, Battista Luciani G, Wells WJ, Allen RB, Lewis AB. Aortic root replacement with the pulmonary autograft in children with complex left heart obstruction. Ann Thorac Surg 1996;62: 442-9.

31. DeLeon SY, Ilbawi MN, Roberson DA, Arcilla RA, Thilenius OG, Wilson WR, et al. Conal enlargement for diffuse subaortic stenosis. J Thorac Cardiovasc Surg 1991;102:814-20.

\section{Discussion}

Dr Michel N. Ilbawi (Chicago, Ill). Subaortic stenosis is a lesion that certainly requires reevaluation in light of our changing understanding of its pathophysiology and management. There are several important issues concerning subaortic stenosis on which you touched that need to be reemphasized. The first is related to the natural history of aortic valve disease in this lesion. The data presented here suggest that aortic valve regurgitation improved in 49 of 51 patients after surgical treatment but fail to show any relationship between age at the time of the operation and postoperative recovery of valve function.

Do you have any data to prove that early surgical intervention prevents subsequent onset of aortic valve disease? This is an important point that might influence timing of surgical intervention, which brings me to my second point.

I noticed that the mean preoperative pressure gradient across the left ventricular outflow tract was about $80 \mathrm{~mm} \mathrm{Hg}$. Moreover, you used a $50 \mathrm{~mm} \mathrm{Hg}$ gradient as your cutoff indication for surgical intervention in symptom-free patients. In view of the facts that surgical risk is low and that progressive septal hypertrophy and distortion of the aortoseptal angle can be increased by prolonged obstruction, why do you prefer to wait until the onset of such a high gradient? Do you believe that earlier intervention might simplify the procedure and decrease recurrence?

The third issue is the extent of surgical resection. We and others believe that in addition to removal of the fibromuscular bridge, extensive myomectomy from commissure to commissure is important to prevent recurrence. You elected to perform membrane removal only or in combination with single myotomy in $75 \%$ of your cases. You showed that the $26 \%$ recurrence rate remained unchanged when myomectomy was added. What was the extent of the myomectomy, and do you agree that a more aggressive approach and myomectomy might reduce the incidence of recurrence?

Finally, the selection of the surgical procedure is important and should be tailored to the individual patient after a thorough exploration and understanding of the underlying pathology. Complex subaortic stenoses, such as tunnel obstruction of normal mitral valve attachment and hypoplastic aortic valve anulus, are best treated with a modified Konno or Konno-Ross procedure as the initial operation. You elected a more conservative approach and performed myotomy or myomectomy in $60 \%$ of these complex subaortic stenosis cases. Finally, what are the current guidelines that you use to decide on the best initial surgical approach in this subgroup of patients?

Dr Serraf. Your first question was related to the natural history of aortic regurgitation in the context of subaortic stenosis. Was there any relationship between the timing of the operation and the incidence of reduction or nonreduction of the aortic valve insufficiency? Unfortunately, we were not able to find in our data any correlation between the age at operation and the development or regression of the aortic insufficiency. In particular, our data cannot confirm that early operation will prevent the occurrence of aortic regurgitation.

To answer your second question, we generally operate on patients with symptoms, meaning that they either have a severe subaortic gradient with some left ventricular hypertrophy already or have aortic regurgitation. This is probably due 
to the more conservative approach of our colleague cardiologists in France. I am not sure, however, that earlier intervention will radically change the natural history of this lesion. Indeed, today's surgical approach does not correct the anatomic substrate that causes the development of subaortic membrane but rather treats the anatomic cause of the left ventricle-aorta gradient. Of course, this does not mean that we have to wait until irreversible myocardial damage has occurred.

The extent of surgical resection has evolved with time. I agree with you that we have to be a little more aggressive. However, I would like you to recall that this is a 17-year retrospective study with close to 3 generations of cardiac surgeons. I would also like to thank Professor Jean Paul Binet,
Professor Jean Langlois, and Professor Ülrich Hvass, who also performed some of these procedures. Roughly, the goal of surgical subaortic resection was initially to obtain a subaortic pathway large enough to pass a Hegar dilator of adequate size through it. Today we are doing a more extensive myectomy to allow us to see the anterior papillary muscle of the mitral valve through the aortic valve.

Finally, for complex subaortic stenosis our indications have changed with the recent advances in the surgical care of these patients. Patients with tunnel subaortic stenosis and hypoplastic aortic anulus are candidates for a Ross-Konno procedure, whereas those with normal aortic anulus are candidates for a modified Konno or septoplasty procedure. 